\title{
The role of NGOs in promoting empowerment for sustainable community development.
}

\begin{abstract}
This paper attempts to illustrate the contribution of NGOs towards sustainable community development. NGOs have many programs, functions and roles which assist community to become empowered, and eventually attain sustainable development. This paper reviews some of these roles, functions and programs of NGOs, such as microfinance, capacity building and self-reliance. Microfinance programs improve the economic well-being of communities by job creation and income generation. In the long run, this economic empowerment will contribute to sustainable community development. NGOs, through capacity building, develop community capacities such as ability, skill and knowledge of mobilizing resources, planning and evaluating community initiation and solving problems to gain the mastery over their lives. It also motivates the community to participate in the projects and help them to improve quality of their lives. Participants are expected to coordinate meetings, plan community activities, and be practical in community initiatives. In this way, NGOs contribute towards sustainable community development. Furthermore, NGOs mobilize the communities to be self-reliant. It assists the communities to discover their own potentials and rely on their own resources. In short, this paper demonstrates that all these programs and functions of NGOs could contribute towards the realization of sustainable community development.
\end{abstract}

Keyword: Microfinance; Capacity Building; Self-reliance; Empowerment. 